\title{
PENGARUH PEMBERIAN ETANOL SECARA AKUT TERHADAP MEMORI KERJA PADA TIKUS (Rattus norvegicus)
}

\author{
Rochman Basuki $^{1}$, Merry Tiyas Anggraini ${ }^{2}$ \\ 1. Bagian Anatomi Fakultas Kedokteran Muhammadiyah Semarang \\ 2. Bagian Kedokteran Keluarga Fakultas Kedokteran Muhammadiyah Semarang \\ Email : rochmanbasuki79@gmail.com
}

\begin{abstract}
Abstrak
Latar belakang : Pemberian etanol secara akut dapat menyebabkan gangguan neurologis, diantaranya cortex prefrontalis (CPF) karena etanol bersifat neurotoksik. Salah satu gangguannya berupa penurunan fungsi memori.

Tujuan Penelitian : Penelitian ini untuk mengetahui adanya pengaruh pemberian etanol secara akut terhadap memori kerja spasial pada tikus.

Metode Penelitian : Penelitian eksperimen dengan desain posttest-only-randomized control ini melibatkan 20 tikus (Rattus norvegicus) yang dibagi menjadi 4 kelompok (K, P1, P2 dan P3) masing-masing 5 ekor. Kelompok P1, P2 dan P3 secara berurutan diberikan etanol 15\% intra peritoneal dengan dosis 1, 2 dan 3 g/kgbb/hr selama 20 hari. Kinerja memori diukur dengan maze radial 8 lengan dengan parameter Number of Error yaitu angka kesalahan tipe A dibagi jumlah lengan yang dimasuki.
\end{abstract}

Hasil Penelitian : Setelah pemberian etanol selama 20 hari, memori kerja spasial antar kelompok diuji dengan Kruskal Wallis. Hasil tidak ada perbedaan yang bermakna, yaitu 0,070 ( $>>0,05)$.

Kesimpulan : Tidak ada hubungan yang bermakna memori kerja spasial pada tikus setelah pemberian etanol secara akut.

Kata kunci : etanol, cortex prefrontalis, memori kerja spasial. 


\section{Abstract}

Background : The acut consumption of ethanol may cause neurological disorders such as the prefrontal cortex (PFC) because ethanol has character neurotoxic. Such as disorders is declining of memory function.

Objective : The purpose of this research is to explain the effect acut consumption of ethanol to spatial memory function on rat.

Methods : This reseach of experimen uses post-test-only-randomized-control design involves rat (Rattus norvegicus) in amount of 20 which are divided into 4 groups (C, P1, P2, and P3) each of the groups includes 5 rat. Group P1, P2, P3 are sequentially distributed by ethanol 15\% intra peritoneal in the dosage of 1, 2, $3 \mathrm{~g} / \mathrm{kg}$ body mass/day for 20 days. Memory performance was measured with eight arm radial maze with parameters Number of error is the error number of type A divided by amount of arm that is entered.

Results : After distributed by ethanol 15\% for 20 days. spatial working memory between groups were tested by Kruskal Wallis. There is not significant difference, which is $0,070(p>0,05)$.

Conclusion: There is not significant relationship spatial working memory on rats after acute ethanol administration.

Keywords: ethanol, prefrontal cortex, spatial working memory.

\section{PENDAHULUAN}

Etanol merupakan cairan senyawa kimia (C, H... OH) yang mudah menguap, tidak berwarna, jernih, dan mempunyai bau khas. ${ }^{19}$ Etanol telah lama digunakan sebagai obat dan terdapat dalam minuman keras seperti bir, anggur dan wiskey. Etanol merupakan senyawa neurotoksik yang mendepresi fungsi sistem saraf pusat (SSP). Etanol di beberapa negara cenderung banyak disalahgunakan..$^{20}$ Minuman mengandung etanol dikonsumsi 75\% populasi di Amerika Serikat dan 10\% diantaranya tidak dapat membatasi (Masters, 2002). Populasi penduduk di Indonesia sekitar 1,5\% merupakan penyalahguna etanol, dengan estimasi terakhir mencapai lima juta jiwa. Kasus penyalahgunaan etanol di Indonesia meningkat rata-rata 28,9 \% per tahun. ${ }^{5}$

Konsumsi etanol secara kronik dapat menimbulkan komplikasi fisik pada SSP berupa perubahan morfologis, neurofisiologis dan biokimiawi, yang berakibat penurunan fungsi kognisi (Mikolajczak et al., 2001). Gangguan memori merupakan salah satu akibat intoksikasi etanol. ${ }^{10}$

Salah satu komponen sistem saraf pusat yang terlibat dalam memori kerja adalah cortex prefrontalis (CPF), dimana CPF memiliki kemampuan untuk menggunakan kembali informasi yang disimpan untuk tindakan yang akan datang. Hal ini disebabkan CPF merupakan salah satu daerah otak yang terlibat dalam sistem neuron dopaminergik. ${ }^{18,4}$

Neuron dopaminergik berasal dari kelompok sel yang terdapat di mesenchephalon, salah satunya meliputi area ventralis tegmenti (AVT). AVT diduga terlibat dalam fungsi memori kerja, jika terjadi destruksi AVT maka fungsi memori kerja akan terganggu akibat defisit dopamin pada daerah tersebut. ${ }^{13,7}$ Meskipun demikian hubungan antara memori kerja dan kadar dopamin pada tikus belum diketahui dengan jelas. ${ }^{16,15,9,2}$

Memori kerja spasial merupakan salah satu bentuk dari memori kerja. Memori kerja spasial memegang peranan penting dalam foraging behavior (tingkah laku mencari makan) pada hewan pengerat dan jenis unggas. ${ }^{1}$ Tikus menunjukkan kemampuan spasial yang luar biasa. Oleh karena itu tikus digunakan sebagai hewan model kemampuan memori spasial dengan maze. Maze radial dengan lengan reward merupakan salah satu alat yang bermanfaat untuk menilai kemampuan memori kerja spasial. ${ }^{6}$ 
Berkaitan dengan latar belakang tersebut perlu dikaji dan diteliti bagaimana pengaruh pemberian etanol secara akut terhadap memori kerja spasial pada tikus.

\section{METODE PENELITIAN}

Alat yang digunakan spuit 3 cc dengan bahan etanol absolut 15\%, aquades, untuk melakukan intervensi etanol secara intraperitoneal pada tikus. Kandang tikus dan timbangan berat badan dan Maze radial 8 lengan.

Maze radial 8 lengan berbentuk lengan oktagonal. Lempeng ini dihubungkan dengan delapan pintu. Lempeng oktagonal di bagian lengan terbuat dari pleksiglas transparan dan lengan maze terbuat dari polivinilklorida buram. Alat ini dikelilingi plastik sehingga tidak memungkinkan tikus merasakan isyarat spasial lain, dan untuk meminimalkan isyarat visual dari sekelilingnya, maze selalu diletakkan pada arah yang sama. Untuk menetralkan stimuli olfaktoris, pelet dibungkus plastik berlubang. Pelet diletakkan dalam cangkir pada ujung-ujung lengan. Di bagian dalam lempeng oktagonal diletakkan silinder terbuat dari aluminium untuk menutup masing-masing pintu masuk ke dalam lengan.

Setiap tikus dari kelompok perlakuan mulai hari pertama sampai hari ke-20 disuntikkan etanol secara intraperitoneal dengan dosis 1 , 2 dan 3 g/kgbb/hari. Pengamatan memori kerja spasial dengan maze mulai dilakukan pada hari ke-21.

Adaptasi maze dilakukan pada kedua kelompok dengan cara sebagai berikut :

1. Hari pertama adaptasi (hari ke-18) tikus dimasukkan ke dalam maze, makanan diletakkan di tiga tempat lengan maze, yaitu di pintu masuk, di pertengahan dan di ujung lengan maze.

2. Pada hari ke-19, adaptasi dilakukan dengan memasukkan tikus ke dalam maze dan meletakkan makanan di dua tempat pada lengan maze, yaitu di bagian tengah dan di ujung lengan maze.

3. Pada hari ke-20, adaptasi diberikan dengan cara memasukkan tikus ke dalam maze dan meletakkan makanan di ujung lengan maze.
4. Selanjutnya selama 12 hari berturut-turut (hari ke21 sampai hari ke-32) dilakukan uji kinerja maze pada kedua kelompok tikus. Tikus diletakkan dalam lempeng silindris dengan arah berlawanan dengan arah peneliti. Pintu gerbang ditutup selama 30 detik agar tikus dapat beradaptasi terlebih dahulu, setelah pintu gerbang diangkat sehingga tikus dapat bergerak bebas ke segala arah. Perlakuan diakhiri setelah tikus memakan semua pelet di seluruh ujung lengan maze atau selama 10 menit. Jika tikus masuk lebih dari setengah lengan maze maka dikategorikan telah memasuki lengan maze dan apabila tikus memasuki lengan maze yang telah dilalui sebelumnya maka tikus dikategorikan salah.

5. Kinerja maze diukur dengan parameter Number of Error, yaitu: Data yang diperoleh dari angka kesalahan tipe A (tikus memasuki kembali lengan yang telah dimasuki sebelumnya) dibagi banyaknya jumlah lengan maze yang dimasuki tikus. Data diambil dengan skala rasio.

\section{HASIL DAN PEMBAHASAN}

\section{Hasil}

Hasil uji maze radial delapan lengan selama 12 hari dibuat Number of Error,yaitu angka kesalahan tipe A dibagi jumlah lengan maze yang dimasuki. Karena pada data angka kesalahan tipe A terdapat angka 0 (nol), maka semua data jumlah lengan maze yang dimasuki dan angka kesalahan tipe A di tranformasikan dengan menggunakan rumus sebagai berikut:

$$
X(t)=\text { square } \operatorname{root}(x+0.5)
$$

Dimana $\mathrm{x}$ adalah nilai awal seadangkan $\mathrm{X}(\mathrm{t})$ adalah nilai yang sudah ditransformasikan (Sokal and Rohlf, 1995).

Pada penelitian ini rerata Number of Error terbanyak pada kelompok kontrol terjadi pada hari ke-11 yaitu 0,71 dan terendah terjadi pada hari ke-9 yaitu 0,44. Kelompok P1 terbanyak pada hari ke-2 yaitu 0,60 dan terendah pada hari ke-7 dan 8 yaitu 0,46. Kelompok P2 
terbanyak pada hari ke-12 yaitu 0,69 dan terendah pada hari ke-6 yaitu 0,45. Kelompok P3 terbanyak pada hari ke-12 yaitu 0,65 dan terendah pada hari ke-9 yaitu 0,46. Dengan demikian keempat kelompok mengalami fluktuasi Number of Error dari hari ke hari (Tabel 1).

Data kinerja memori pada keempat kelompok berupa pengukuran skala rasio maka untuk menguji normalitas data menggunakan uji Shapiro-Wilk $(<50)$ yang diperoleh hasil $\mathrm{p}=0,005(\mathrm{p}<0,05)$, artinya distribusi data tidak normal maka dilakukan transformasi data. Setelah ditransformasi data diperoleh hasil $\mathrm{p}=0,000$ $(\mathrm{p}<0,05)$. Dengan demikian tidak memenuhi syarat uji Two way ANOVA, maka data dilakukan uji Kruskal
Wallis (Dahlan, 2011). Pada uji Kruskal Wallis diperoleh hasil $\mathrm{p}=0,070(\mathrm{p}>0,05)$, artinya tidak ada perbedaan bermakna Number of Error pada keempat kelompok.

\section{PEMBAHASAN}

Hasil Pada penelitian ini untuk mengetahui adanya perbedaan tampilan memori kerja antar kelompok setelah pemberian etanol selama 20 hari dengan melihat parameter Number of Error, yang menggambarkan kemampuan memori kerja spasial tikus dalam 12 hari pada kinerja maze. Semakin sedikit Number of Error yang dilakukan semakin baik tampilan memori kerja spasial tikus.

Tabel 1. Rerata dan standar deviasi Number of Error

\begin{tabular}{|c|c|c|c|c|}
\hline \multirow{2}{*}{ Hari } & \multicolumn{4}{|c|}{ Kelompok } \\
\cline { 2 - 5 } & $\mathrm{K}$ & $\mathrm{P} 1$ & $\mathrm{P} 2$ & $\mathrm{P} 3$ \\
\hline 1 & $0,46 \pm 0,11$ & $0,50 \pm 0,10$ & $0,59 \pm 0,15$ & $0,50 \pm 0,13$ \\
\hline 2 & $0,53 \pm 0,11$ & $0,60 \pm 0,16$ & $0,65 \pm 0,05$ & $0,49 \pm 0,17$ \\
\hline 3 & $0,45 \pm 0,11$ & $0,49 \pm 0,12$ & $0,52 \pm 0,17$ & $0,54 \pm 0,16$ \\
\hline 4 & $0,55 \pm 0.25$ & $0,46 \pm 0,14$ & $0,66 \pm 0,10$ & $0,56 \pm 0,12$ \\
\hline 5 & $0,53 \pm 0,06$ & $0,53 \pm 0,10$ & $0,56 \pm 0,07$ & $0,51 \pm 0,14$ \\
\hline 6 & $0,56 \pm 0,18$ & $0,50 \pm 0,10$ & $0,45 \pm 0,02$ & $0,53 \pm 0,15$ \\
\hline 7 & $0,51 \pm 0,06$ & $0,46 \pm 0,13$ & $0,50 \pm 0,10$ & $0,58 \pm 0,11$ \\
\hline 8 & $0,46 \pm 0,14$ & $0,46 \pm 0,11$ & $0,52 \pm 0,05$ & $0,57 \pm 0,13$ \\
\hline 9 & $0,44 \pm 0,12$ & $0,59 \pm 0,14$ & $0,55 \pm 0,16$ & $0,46 \pm 0,14$ \\
\hline 10 & $0,45 \pm 0,11$ & $0,56 \pm 0,12$ & $0,59 \pm 0,22$ & $0,58 \pm 0,17$ \\
\hline 11 & $0,71 \pm 0,21$ & $0,52 \pm 0,17$ & $0,52 \pm 0,18$ & $0,47 \pm 0,28$ \\
\hline 12 & $0,49 \pm 0,09$ & $0,50 \pm 0,14$ & $0,69 \pm 0,08$ & $0,65 \pm 0,08$ \\
\hline
\end{tabular}

Dengan uji Kruskal Wallis terhadap Number of Error diperoleh tidak ada perbedaan yang bermakna, yaitu 0,070 ( $p>0,05)$. Dengan demikian dapat disimpulkan bahwa setelah pemberian etanol secara akut tidak ada perbedaan bermakna tampilan memori kerja spasial antar kelompok. Hal ini berbeda dengan penelitian Narwanto et al., (2008), bahwa pemberian etanol selama 1 bulan (kronik) dengan dosis 1, 2 dan 3 g/kgbb/hari diperoleh adanya perbedaan yang bermakna memori kerja spasial antara kelompok kontrol dan kelompok perlakuan. Pada penelitian ini menunjukkan bahwa pemberian etanol selama 20 hari belum bisa memberikan efek pada SSP, khususnya yang berperan dalam memori kerja karena pemberian yang bersifat akut. Kelemahan maupun keterbatasan dalam penelitian ini hanya menggunakan satu pengukuran dengan Number of Error sehingga tidak bisa menganalisa hasil data yang lain. Dengan demikian pemberian etanol 15\% selama 20 hari tidak memberikan pengaruh terhadap memori kerja spasial pada tikus. 


\section{KESIMPULAN}

Berdasarkan hasil penelitian ini dapat diambil kesimpulan sebagai berikut :

Pemberian etanol 15\% selama 20 hari dengan dosis 1 , 2 dan $3 \mathrm{~g} / \mathrm{kgbb} / \mathrm{hari}$ tidak memberikan pengaruh tampilan memori kerja spasial pada tikus.

Untuk penelitian selanjutnya, perlu dikembangkan sebagai berikut :

1. Perlu dilakukan penelitian lebih lanjut adanya apoptosis pada sel-sel cortex prefrontalis setelah pemberian etanol secara akut.

2. Perlu dilakukan penelitian lebih lanjut tentang keterlibatan cortex prefrontalis dalam fungsi yang lain (memori kerja) akibat pengaruh pemberian etanol secara kronik.

3. Perlu dilakukan penelitian lebih lanjut dengan pemberian obat misalnya antioksidan atau senyawa yang lain yang dapat menghambat perubahan morfologis yang terjadi akibat penggunaan etanol.

\section{DAFTAR PUSTAKA}

1. Bustos G, Basoalto E, Pinto-Hamuy T. 2003. Spatial Memory in Long Evans and Rattus Norvegicus Rats, Biol res., 36 : 193-9.

2. Cai JX and Arnsten AF. 1987. Dose-Dependent Effects of the Dopamin D1 Reseptor Agonists A77636 or SKF81297 on Spatial Working Memory in Aged Monkeys . J. of Neuroscience, Vol. 283, Issue 1, 183-189.

3. Dahlan MS. 2011. Statistik untuk Kedokteran dan Kesehatan. Edisi 5. Medika Salemba, Jakarta.

4. Diamond 1991. Guidelines for the study of brainbehavior relationships during development. In: Levin, H.S., Eisenberg, H.M. and Benton, A.L. (Eds.) Frontal Lobe Function and Dysfunction, New York: Oxford Univ. Press, pp. 339-378.

5. Djatmiko P. 2007. Berbagai Indikator Taraf Kesehatan Jiwa Masyarakat. Availablefrom:http;//pdskji jaya. org/index.php?option=comcontent\&task=view \&id $=110$ \&itemld +1 .
6. Dogru EJ, Gumusba U and Kara F. 2003. Individual Variation in the Spatial Reference and Working Memory Assased under Allothetic and Idiothetic OrientationCues in Rat, Acta neurobiol. Exp., 63: 17-23.

7. Fellous J and Suri RE. 2002. The Roles of Dopamine. The handbook of brain thory \& neural network, $2^{\text {nd }}$ edition, Cambridge.

8. Fried I, Wilson CL, Morrow JW, Ameron KA, Behnke ED, Ackerson LC \& Maidment NT. 2001 Increased Dopamine Release in The Human Amygdala Durind Performance of Cognitive Tasks. Nature Review Neuroscience, 4(2) : 201-206.

9. Kolb B and Wishaw IQ. 1990. Fundamentals of Human Neuropsychology. Third Edition. NY : W. H. Freeman ang Company.

10 Ling W, Compton P, Rawson R and Wesson DR. 2003. Neuropsychiatry of Alkohol and Drug Abuse. Neuropsychiatry, $2^{\text {nd }}$ edition, Philadelpia; Lippincotn Williams \& Wilkins.

11. Masters SB. 2002. Alkohol. Dalam: Katzung BG. Farmakologi Dasar dan Klinik. Edisi 8, Salemba Medika, Jakarta.

12. Mikolajczak P, Korazyn IO, Nowaczyk M and Kaminska E. 2001. Ethanol Exposure on Spatial Cognitive Processing and Hippocampal Function in the Rat, Hippocampus, $10: 122-30$.

13. Moal ML. 2000. Mesocorticolimbic Dopaminergic Neurons Functional \& Regulatory Roles, http:// www.acnp.org/G4/GN401000025 / CH025.html

14. Narwanto MI, Aswin S dan Mustofa. 2008. Pengaruh Pemberian Etanol Jangka Panjang terhadap Jumlah Reseptor D1 Dopamin Piramidal di CA1 dan CA3 Hippocampus dan Memori Kerja Spasial pada Tikus Remaja.

15. Petrides M. 2000. Mapping CPF Cortex Sistem for the Control of Cognition. In: Toga, A. W(ed). Brain Mapping. The Sistem. San Diego : Academic Press.

16. Rakic PG. 1992. Working Memory and the Mind. In:Damasio, A.(eds). 1996. American:Scientific American Book of the Brain, pp. 91-104. 
17. Sokal RR, Rohlf FJ. Biometry. 1995.The principles and practice of statistics in biological research. 3rd ed. W. H. Freeman \& Co, New York.

18. Snell RS. 2006. Neuroanatomi Klinik. Edisi 5. EGC, Jakarta.

19. William J and Reilly JB. 2000. Pharmaceutical Necessities, Remington The Science and Practice of Pharmacy, edt Alfonso, R. G, 20 ${ }^{\text {th }}$ edition, Lippincott William \& Wilkins, Philadelpia.

20. Wiria MS. 2007. Farmakologi dan Terapi. Edisi 5. FKUI, Jakarta. 